Journal of Computer Science 7 (6): 859-864, 2011

ISSN 1549-3636

(C) 2011 Science Publications

\title{
Fuzzy Logic Controller for Static Synchronous Series Compensator with Energy Storage System for Transient Stability Analysis
}

\author{
${ }^{1}$ Sona Padma and ${ }^{2} \mathrm{M}$. Rajaram \\ ${ }^{1}$ Department of Electrical and Electronics Engineering, \\ College of Technology, Salem, Tamilnadu, India \\ ${ }^{2}$ Vice-Chancellor, Anna University of Technology, Tirunelveli, India
}

\begin{abstract}
Problem statement: FACTS devices play a major role in the efficient operation of the complex power system. FACTS devices such as STATCOM, SSSC and IPFC are in increasing usage. With energy storage systems they have a good control over the real as well as reactive power compensation and transient stability improvement. The design of controller for the SSSC with SMES system is analyzed in this study. Approach: The main variables to be controlled in the power system for efficient operation are the voltage, phase angle and impedance. A SSSC is a series connected converter based FACTS control which can provide a series reactive power compensation for a transmission system. With the addition of energy storage device, in addition to the reactive power compensation the real power exchange is also accomplished. Fuzzy logic controller is designed for the efficient operation of the power system with SSSC integrated with energy storage device. From the power reference the current reference is calculated and the error and change in error in the current are calculated in the controller. Results: A three phase to ground fault is simulated in the test system. A comparative analysis of the PI and fuzzy logic control of SSSC with energy storage system for the rotor angle oscillation damping following the disturbance is done. Conclusion: The fuzzy logic controller works efficiently compared to the conventional PI controller for the SSSC with SMES system. Also with energy storage system in the FACTS devices, the efficient operation of the power system is possible.
\end{abstract}

Key words: Flexible AC transmission systems, energy storage system, fuzzy logic control, static synchronous series compensator, transient stability, electric utilities, electronic inverters, power system, computational burden, magnetic field, injected voltage, voltage source inverter, Superconducting Magnetic Energy Storage System (SMES)

\section{INTRODUCTION}

FACTS controllers are capable of controlling the network condition in a very fast manner and this unique feature of FACTS can be exploited to improve the stability of a power system (Panda, 2010; Kumkratug, 2010). The detailed explanations about the FACTS controllers are well documented in the literature. Static Synchronous Series Compensator (SSSC) is one of the important members of FACTS family which can be installed in series in the transmission lines for applications such as increased power transfer, improved transient and small disturbance stability of power systems (Abido, 2009; Shakarami and Kazemi, 2010). SSSC is very effective in controlling power flow in a transmission line with the capability to change its reactance characteristic from capacitive to inductive.
Electric utilities are operating in an increasingly competitive environment due to the recent trend of deregulation. At the same time, economic and environmental pressures limit their possibilities to further expand their transmission facilities (Makkar and Dewan, 2010). The recent power electronic devices have made the FACTS devices of special interest to power system operation and transmission providers (Saha, 2010). The recent power electronic inverters not only alter the power transfers between the AC network and the energy storage, but produce instant variations of reactive power without drawing on the stored energy. Also, the output of the energy storage device can be varied in a fraction of second (Sahay and Dwivedi, 2009; Heussen et al., 2010). This study proposes a Superconducting Magnetic Energy Storage System (SMES) for integration with the SSSC. The

Corresponding Author: Sona Padma, Department of Electrical and Electronics Engineering, College of Technology, Salem, Tamilnadu, India 
characteristics of a SMES system-the rapid response (milli-second), high power (multi-MW), high efficiency and four quadrant control offer very desirable benefits to the power utility industry. As the utilization of transmission line assets becomes a substantial contribution to utility income and as significant power transfer variations may occur at short time notice in a deregulated environment, SMES will become very attractive. An SMES device can also have a positive cost and environmental impact by reducing fuel consumption and emissions through reduced line losses.

An SMES device is a dc current device that stores energy in the magnetic field. The dc current flowing through a superconducting wire in a large magnet creates the magnetic field. Generally it consists of the superconducting coil, the cryogenic system and the power conversion/conditioning system with control and protection function. In order to achieve the best system configuration possible, the design of the SMES system needs to take into account many factors. In order to reduce the computational burden, an equivalent circuit of the coil is represented by a 6-segment model comprised of self inductances, mutual couplings, ac loss resistances and series and shunt capacitances.

Modeling of SSSC: The conventional series capacitor provides a voltage across it even though it includes a capacitive reactance in series with the transmission line. The concept of SSSC is the same voltage can be provided by a voltage source.

The basic model of the series compensator with a voltage source is shown in Fig. 1. The above basic model is obtained with the help of a series FACTS device called SSSC. It consists of a voltage-sourced converter and a transformer connected in series with a transmission line. The SSSC injects a voltage of variable magnitude in quadrature with the line current, thereby emulating an inductive or capacitive reactance. This emulated variable reactance in series with the line can then influence the transmitted electric power. A 48 pulse Voltage Source Inverter (VSI) is used. With 48 pulse VSI, AC filters are not required. Ideal switches and zigzag phase shifting transformers are used to build a GTO- type VSI. The inverter consists of four 3-phase, 3-level inverters and four phase shifting transformers. Such a configuration is harmonic neutralized. The DC bus is connected to the four 3-phase inverters. The four voltages generated by the inverters are applied to secondary windings of four zigzag phase shifting transformers. The four transformers' primary windings are connected in series and the converter pulse patterns are phase shifted so that the four voltage fundamental components sum in phase on the primary side. The configuration is such that it neutralizes upto 45th harmonic (Ustun and Mekhilef, 2009; 2010; Padma and Lakshmipathi, 2010).

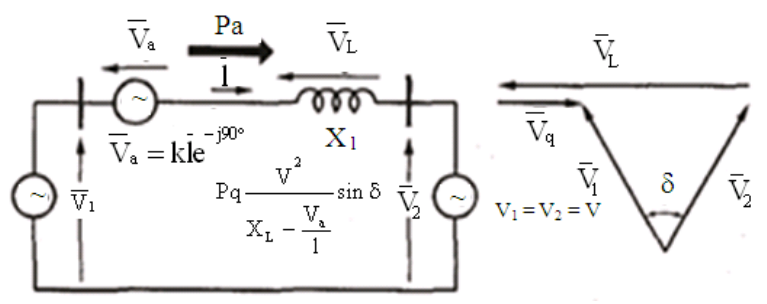

Fig. 1: Basic model of the series compensation with a voltage source

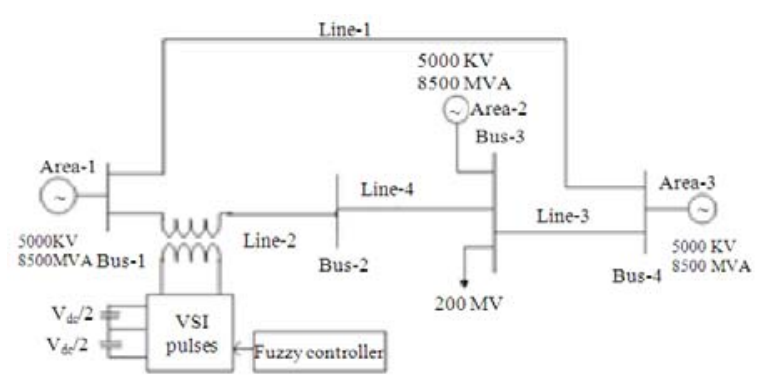

Fig. 2: Single line diagram of the test system

The test system considered for analysis is shown in Fig. 2. In the test system the SSSC located in series with line L1 between buses 1 and 2. It has a rating of 100MVA and is capable of injecting up to $10 \%$ of the nominal system voltage.

Control scheme for SSSC: The main function of the SSSC is to dynamically control the power flow over the transmission line. The earlier control schemes proposed were based on the line impedance control mode in which the SSSC compensating voltage is derived by multiplying the current amplitude with the desired compensating reactance $X_{\text {qref }}$. Since it is difficult to predict $\mathrm{X}_{\text {qref }}$ under varying network contingencies, the voltage control mode is considered in the proposed scheme. This controller is modified to operate the SSSC in the automatic power flow control mode. In the automatic power flow control mode, the reference inputs to the controller are reference powers $\mathrm{P}$ and $\mathrm{Q}$, which are to be maintained in the transmission line despite system changes. Using dq transformation the line voltage and the current are converted to corresponding $\mathrm{d}$ and $\mathrm{q}$ axis components. The power references are converted to current references using the Eq. 1 and 2. From the current references the sigma angle is calculated and then the firing pulses are generated. The MATLAB/SIMULINK model is shown in Fig. 3. 
$I_{\text {dref }}=\left(P \times V_{d}+Q \times V_{q}\right) /\left(V^{2}{ }_{d}+V^{2}{ }_{q}\right)$

$\mathrm{I}_{\text {dref }}=\left(\mathrm{P} \times \mathrm{V}_{\mathrm{q}}+\mathrm{Q} \times \mathrm{V}_{\mathrm{d}}\right) /\left(\mathrm{V}_{\mathrm{d}}^{2}+\mathrm{V}_{\mathrm{q}}{ }_{\mathrm{q}}\right)$

where, $\mathrm{I}_{\text {dref }}$ and $\mathrm{I}_{\text {qref }}$ are the reference currents calculated from the $\mathrm{d}$ and $\mathrm{q}$ axis voltages $\mathrm{V}_{\mathrm{d}}$ and $\mathrm{V}_{\mathrm{q}}$.

Fuzzy logic control for SSSC: Fuzzy logic control has gained very much interest in recent years. A numbers of successful applications have been reported and these applications of the fuzzy control have often produced results superior to those of classical control (Pratumsuwan et al., 2010). This increased popularity of the fuzzy control can be attributed to the fact that fuzzy logic systems provide a powerful vehicle that allows engineers to incorporate human reasoning in the control algorithm. The fuzzy logic system design is not based on the mathematical model of process (Samuel, 2010). The fuzzy controllers designed using fuzzy logic implements human reasoning that has been programmed into membership functions, fuzzy rules and rule interpretation. The fuzzy logic controller involves four main stages: fuzzification, rule base, inference mechanism and defuzzification (Sivanandam and Deepa, 2009). The structure of the fuzzy logic controller is shown in Fig. 4.

The error and change in error are taken as the inputs to the fuzzifier. Triangular membership functions are used for the inputs and the output. The universe of discourse for both the inputs is divided into seven partitions (NL - Negative Large, NM - Negative Medium, NS - Negative Small, Z - Zero, PS - Positive Small, PM - Positive Medium, PL - Positive Large). The output is the voltage and again the universe of discourse is divided into seven partitions. The details of the partitions for the inputs and the output are shown in Fig. 5. Heuristic methods are used in the formation of rule base. The rule base is of the form "If input1 is \{\} and input 2 is \{\} then output is \{\} ". The rule base table is shown in Table 1 . The inference mechanism depending on the inputs evaluates output surface based on the rule base. Mamdani type of fuzzy inference system is used. The centroid method of defuzzification is used to obtain the crisp output.

Integration of SSSC with SMES: The Energy storage devices are widely used in power system with the following objectives: ability to absorb harmonics, provide load leveling, provide damping of inter-area oscillations, help in damping transient stability and provide effective and fast control power flow along a transmission line corridor. The various energy storage technologies adopted were, the battery energy storage, flywheel energy storage, advanced super capacitors and super conducting magnetic energy storage systems. The key factors in selecting an energy storage system depends upon the amount of energy that can be stored in the device and the rate at which the energy can be transferred into or out of the storage device.

Table 1: Rule base table

\begin{tabular}{llllllll}
\hline 1 & & & & & & \\
2 & NL & NM & NS & Z & PS & PM & PL \\
\hline NL & Z & NS & NM & NL & NL & NL & NL \\
NM & PS & Z & NS & NM & NL & NL & NL \\
NS & PM & PS & Z & NS & NM & NM & NL \\
Z & PM & PM & PS & Z & NS & NM & NM \\
PS & PL & PM & PS & PS & Z & NS & NM \\
PM & PL & PL & PM & PM & PS & Z & NS \\
PL & PL & PL & PL & PL & PM & PS & Z \\
\hline
\end{tabular}

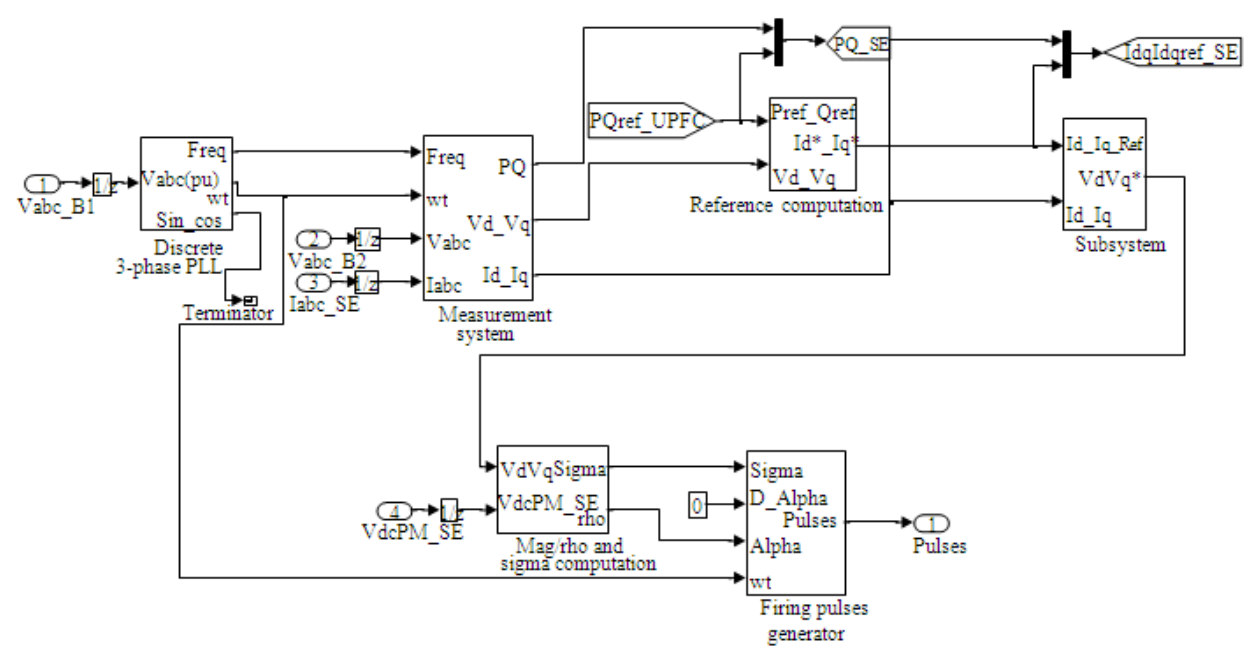

Fig. 3: MATLAB SIMULINK model for the generation of firing pulses 


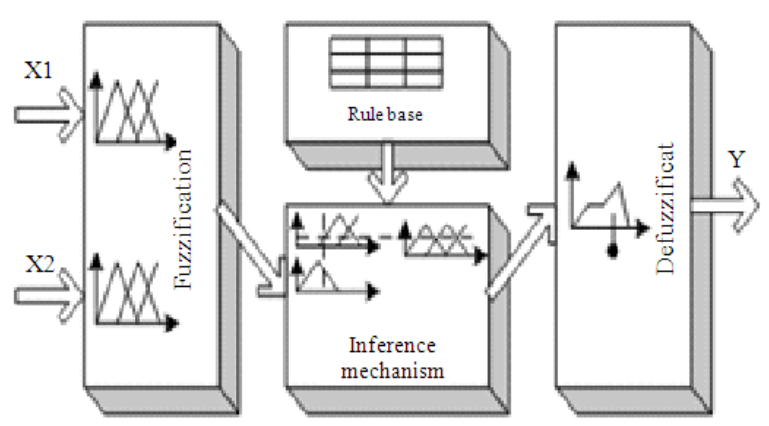

Fig. 4: Structure of the fuzzy logic controller

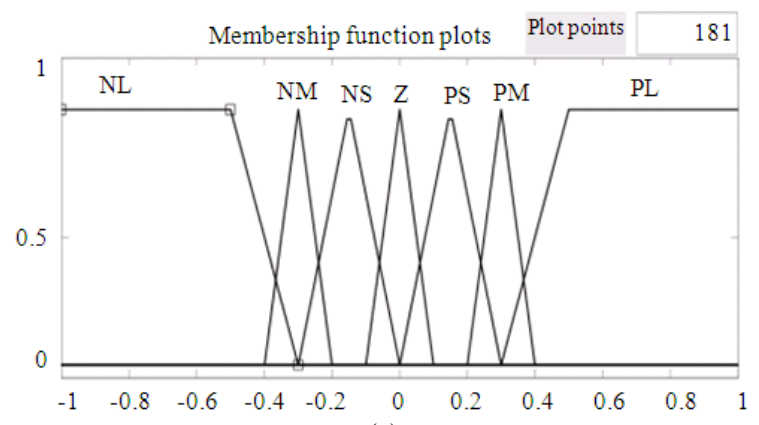

(a)

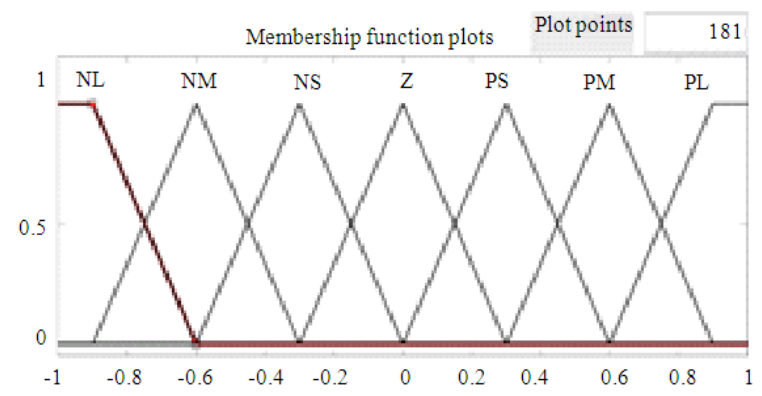

(b)

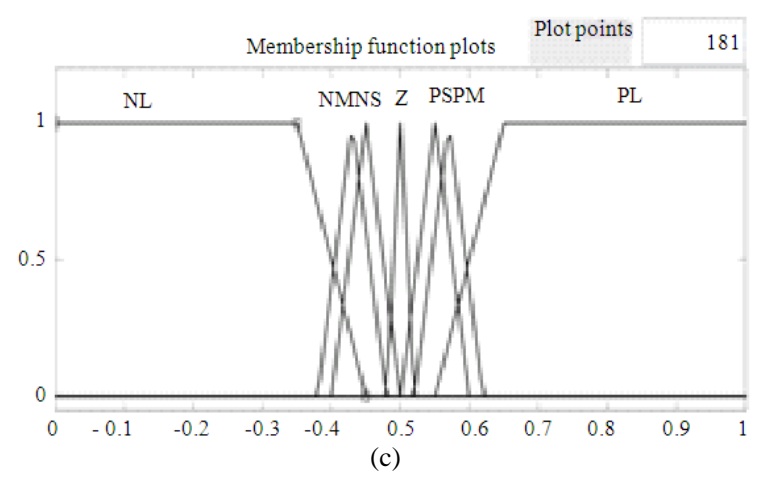

Fig. 5: Membership functions for the inputs 1 and 2 (a and b) and the output (c)

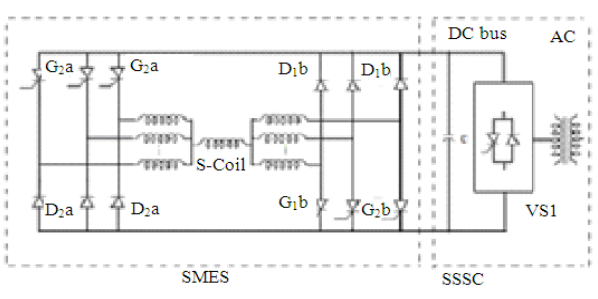

Fig. 6: Two quadrant n-phase chopper

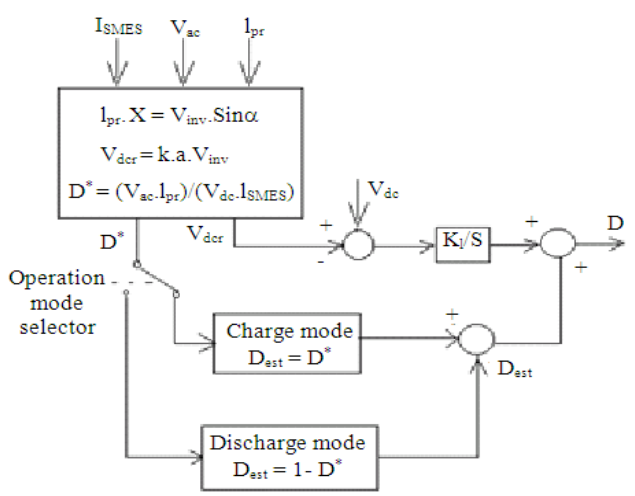

Fig. 7: Block diagram of the internal control scheme for chopper control

Interfacing SMES with VSI: A superconducting magnetic energy storage containing electronic converters rapidly injects and/or absorbs the real and/or reactive power or dynamically controls the power flow in an ac system. Since the dc current in the magnet does not change rapidly, the power input or output of the magnet is changed by controlling the voltage across the magnet with a suitable electronics interface. An electronic interface known as chopper is needed between the energy source and the VSI. For VSI the energy source compensates the capacitor charge through the electronic interface and maintains the required capacitor voltage. Two-quadrant n-phase DCDC converter as shown in Fig. 6 is adopted as interface. Here ' $n$ ' is related to the maximum current driven by the superconducting device. The DC-DC chopper solves the problems of the high power rating requirements imposed by the superconducting coil to the SSSC. It allows to reduce the ratings of the overall power devices by regulating the current flowing from the superconducting coil to the inverter of the SSSC (Padma and Lakshmipathi, 2010). It is composed of many shunt connected diode-thyristor legs that permit the driving of the high current ratings stored in the superconducting coil. In this study two-quadrant three phase chopper is taken.

Internal control scheme for chopper control: The control block diagram for the determination of the duty cycle for the chopper is shown in Fig. 7. The 
relationship between the DC bus voltage and the output voltage of the inverter is given by the Eq. 3 :

$\mathrm{V}_{\mathrm{dcr}}=\mathrm{k}_{\mathrm{a}} \mathrm{V}_{\mathrm{inv}}$

where, $\mathrm{k}_{\mathrm{a}}=\mathrm{k} \times \mathrm{a}, \mathrm{k}$ is the Pulse number and $\mathrm{a}$ is the ratio of the coupling transformer.

The chopper is operated in a step down configuration in the charge mode of the superconducting coil. Here, the set of thyristors "a" are operated with the duty cycle ' $D$ ' while the set of thyristors "b" are kept on at all times. The relationship between the coil voltage and the DC bus voltage is given by the Eq. 4 as:

$\mathrm{V}_{\mathrm{SMES}}=\mathrm{D} \times \mathrm{V}_{\mathrm{DC}}$

In the discharge mode, the chopper is operated in a step-up configuration. The set of thyristors "b" is operated with duty cycle D while the set of thyristors "a" is kept off at all times. The relationship between the coil voltage and the DC bus voltage is given by the Eq. 5 as:

$-\mathrm{V}_{\mathrm{SMES}}=(1-\mathrm{D}) \times \mathrm{V}_{\mathrm{DC}}$

The duty cycle ranges from $0-1$. The value of $K_{I}$ is taken as 23.2 by trial and error method. The duty cycle $\mathrm{D}$ is estimated from the active power ratings that the SSSC should inject from the voltage at the DC bus and from the current stored into the SMES coil $\left(\mathrm{V}_{\mathrm{ac}} . \mathrm{I}_{\mathrm{pr}}\right)$. This estimated value of $D_{\text {est }}$ is adjusted through a closed loop control whose function is eliminating the voltage error between the calculated and the real voltage ratings at the DC bus.

\section{RESULTS}

The PI and fuzzy controls are applied for the test system with SSSC integrated with superconducting energy storage device. Case (a) is discussed for the PI control for 48-pulse inverter based SSSC integrated with SMES and case (b) is discussed for the fuzzy control for 48-pulse inverter based SSSC integrated with SMES and are simulated using MATLAB/Simulink to analyze its operation. A three phase fault is created to study the performance of the controllers. The fault is created in the line 2 near the SSSC at $0.4 \mathrm{~s}$ and it is cleared at $0.5 \mathrm{~s}$.

Figure 8 and 9 show the rotor angle oscillations in area1 for cases (a) and (b) respectively. Figure 10 and 11 show the rotor angle oscillations in area2 for cases (a) and (b) respectively. Figure 12 and 13 show the injected voltage from the SSSC for cases (a) and (b) respectively.

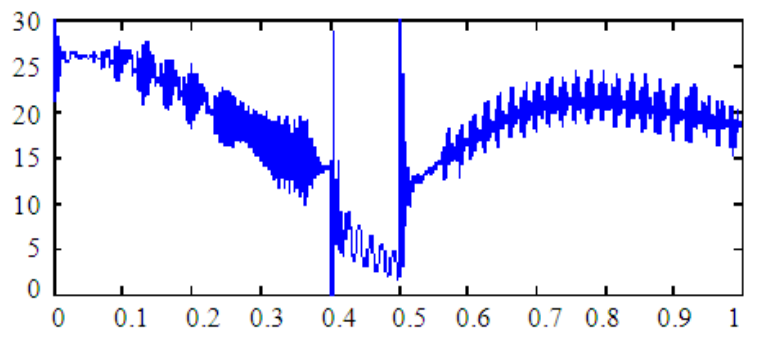

Fig. 8: Rotor angle oscillations in area1 (case a)

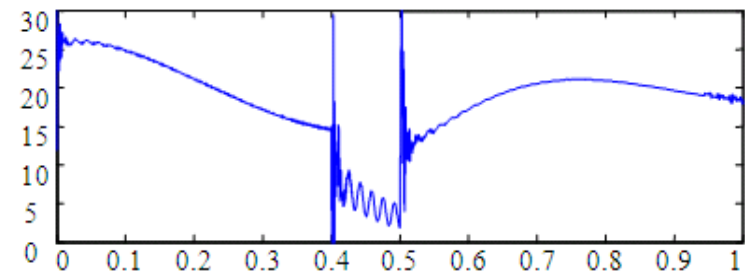

Fig. 9: Rotor angle oscillations in area1 (case b)

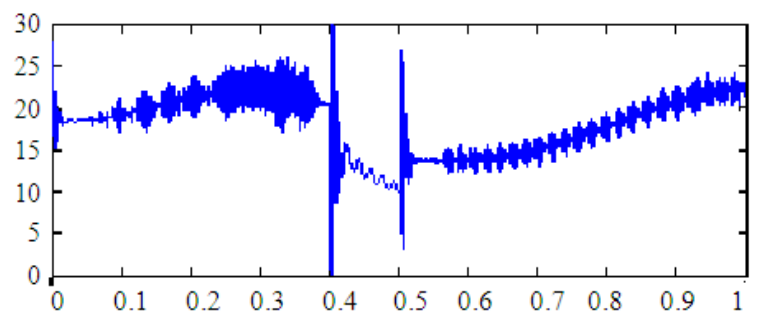

Fig.10: Rotor angle oscillations in area2 (case a)

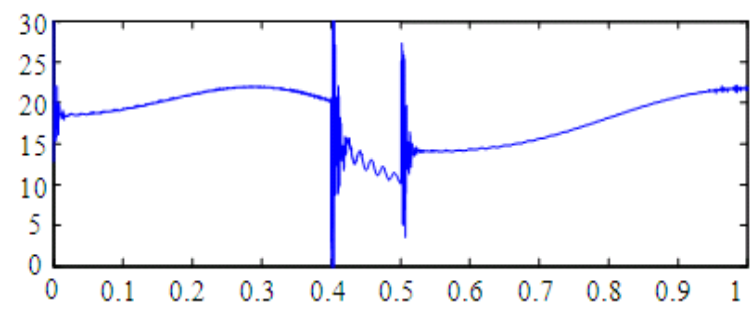

Fig. 11: Rotor angle oscillations in area 2 (case b)

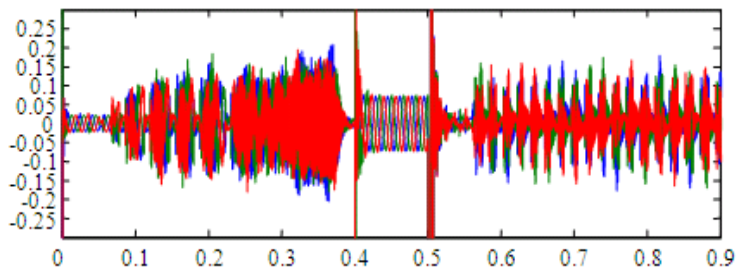

Fig. 12: Injected Voltage from SSSC (case a) 


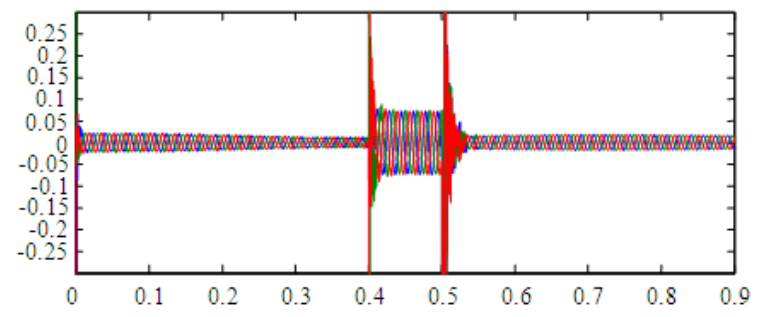

Fig. 13: Injected Voltage from SSSC (case b)

\section{DISCUSSION}

The oscillations are much reduced in the case of fuzzy controller compared to the PI controller. It is clear from the figures that the overshoot as well as oscillations are very much improved for the case (b) compared to (a) in all the waveforms. Hence the fuzzy controller is effective in damping out the oscillations in a better way compared to the conventional controller. The energy storage system also helps in improving the transient stability.

\section{CONCLUSION}

The damping of rotor angle oscillations of a multiarea system is analysed with PI and fuzzy logic controller for SSSC integrated with energy storage system. Here the Superconducting Magnetic Energy Storage system is taken for the analysis. 48 pulse voltage source inverter is adopted for the generation of injected voltage. Two quadrant three phase chopper control is connected for the interfacing of the voltage source inverter and the energy storage device. Three phase fault is simulated in the system near the SSSC in line 2. It is inferred from the results, that the damping of rotor angle oscillations for the system with SMES using Fuzzy logic controller is better compared to the PI controller.

\section{ACKNOWLEDGEMENT}

We sincerely thank the Management, Secretary and Principal of Sona College of Technology, Salem for their complete support in doing this research work.

\section{REFERENCES}

Abido, M.A., 2009. Power system stability enhancement using FACTS controllers: A review. Arabian J. Sci. Engineer., 34: 153-172.

Heussen, K., S. Koch, A. Ulbig and G. Anderson, 2010. Energy Storage in Power System Operation: The Power nodes modeling framework. Proceedings of the Innovative Smart Grid Technologies Conference Europe, (ISGTCE'10), ISGT Europe, pp: $1-8 . \quad$ DOI: 10.1109/ISGTEUROPE.2010.5638865
Kumkratug, P., 2010. Power system stability enhancement using unified power flow controller. Am. J. Applied Sci., 7: 1504-1508. DOI: 10.3844/ajassp.2010.1504.1508

Makkar, C.R. and L. Dewan, 2010. Transient Stability Enhancement using Robust FACTS Controllers- A Brief Tour. Canadian J. Elect. Electron. Engineer., 1: 150-155.

Padma, S. and R. Lakshmipathi, 2010. Static Synchronous Series Compensator (SSSC) with Superconducting Magnetic Energy Storage (SMES) for the enhancement of transient stability in multi-area system. Proceedings of the International Conference on Advances in Electrical and Electronics, Tamilnadu, India, pp: 39-43.

Panda, S., 2010. Modelling, simulation and optimal tuning of SSSC-based controller in a multimachine power system. World J. Model. Simulation, 6: 110-121.

Pratumsuwan, P., S. Thongchai and S. Tansriwong, 2010. A hybrid of fuzzy and proportional-integralderivative controller for electro-hydraulic position servo system. Energy Res. J., 1: 62-67. DOI: 10.3844/erjsp.2010.62.67

Saha, S.K., 2010. Reliability contingency analysis by static synchronous series compensator in optimal power flow. Int. J. Comput. Elect. Engineer., 2: 908-911.

Sahay, K. and B. Dwivedi, 2009. Supercapacitors energy storage system for power quality improvement: An overview. J. Elect. Syst. http://journal.esrgroups.org/jes/papers/5_4_8.pdf

Samuel, N.N., 2010. An intelligent fuzzy logic controller applied to multi-area load frequency control. Am. J. Sci. Ind. Res., 1: 220-226. DOI: 10.5251/ajsir.2010.1.2.220.226

Shakarami, M.R. and A. Kazemi, 2010. Robust design of static synchronous series compensator-based stabilizer for damping inter-area oscillations using quadratic mathematical programming. J. Zhejiang Univ.-Sci. $\quad$ C., $\quad 11$ : 296-306. DOI: 10.1631/jzus.C0910428

Sivanandam, S.N. and S.N. Deepa, 2009. Principles of Softcomputing (W/Cd). 1st Edn., Wiley India Pvt. Ltd., India, ISBN-10: 8126510757, pp: 762.

Ustun, T.S. and S. Mekhilef, 2009. Power Line Compensation Study of a Static Synchronous Series Compensator (SSSC) based on soft switching 48-Pulse PWM inverter on the power demand from the grid. Australian J. Basic Applied Sci., 3: 1301-1314.

Ustun, T.S. and S. Mekhilef, 2010, Effects of a Static Synchronous Series Compensator (SSSC) based on a soft switching 48-pulse pwm inverter on the power demand from the grid. J. Power Elect., 10: 85-90. 